\title{
Technical Note: An Automated System for Separate Combustion of Elemental and Organic Carbon for ${ }^{14} \mathrm{C}$ Analysis of Carbonaceous Aerosol
}

\author{
Ulrike Dusek $^{1 *}$, Max M. Cosijn ${ }^{1}$, Haiyan Ni ${ }^{1,2}$, Ru-Jin Huang ${ }^{2}$, Harro A.J. Meijer ${ }^{1}$, \\ Steven van Heuven ${ }^{1}$ \\ ${ }^{1}$ Centre for Isotope Research (CIO), Energy and Sustainability Research Institute Groningen (ESRIG), University of \\ Groningen, Groningen, 9747 AG, The Netherlands \\ ${ }^{2}$ State Key Laboratory of Loess and Quaternary Geology, Key Laboratory of Aerosol Chemistry and Physics, Center for \\ Excellence in Quaternary Science and Global Change, Institute of Earth Environment, Chinese Academy of Sciences, \\ Xi'an 710061, China
}

\begin{abstract}
We present the design and evaluation of an automated system for the conversion of elemental and organic carbon aerosol to $\mathrm{CO}_{2}$ for subsequent radiocarbon analysis. The system allows heating the sample in pure oxygen or helium at user defined temperature steps, followed by catalytic conversion of incomplete carbonaceous combustion products to $\mathrm{CO}_{2}$. The resulting $\mathrm{CO}_{2}$ is quantified using an NDIR detector and can be separated from other combustion by-products in a reduction oven. The purified $\mathrm{CO}_{2}$ is cryogenically collected in glass ampoules that can be sealed for storage until ${ }^{14} \mathrm{C}$ analysis. We show that (1) the $\mathrm{CO}_{2}$ amount measured by the calibrated NDIR sensor compares well to an independent manometric method, (2) that we successfully remove combustion by-products such as $\mathrm{SO}_{2}, \mathrm{H}_{2} \mathrm{O}$, and $\mathrm{NO}_{x}$, resulting in pure $\mathrm{CO}_{2}$ samples, and (3) that the system has low contamination and negligible cross contamination making it ideal for the analysis of very small samples in the order of $10-50 \mu \mathrm{gC}$.
\end{abstract}

Keywords: Carbonaceous aerosol; Radiocarbon; Automated pre-treatment system; Organic and elemental carbon separation.

\section{INTRODUCTION}

Radiocarbon analysis is a powerful tool for the source apportionment of carbonaceous aerosol and has been used to successfully identify main pollution sources in various areas of the globe (Currie, 2000; Szidat et al., 2006; Gustafsson et al., 2009; Glasius et al., 2011; Heal, 2014; Liu et al., 2014; Zotter et al., 2014; Winiger et al., 2015; Dusek et al., 2017; Zhang et al., 2017). Radiocarbon measurements are done with accelerator mass spectrometers (AMS), which measure the ratio of ${ }^{14} \mathrm{C} /{ }^{12} \mathrm{C}$ either on pure $\mathrm{CO}_{2}$ or on graphite targets (van der Plicht et al., 2000; Ruff et al., 2007; Synal et al., 2007; Povinec et al., 2009; de Rooij et al., 2010). Therefore, the carbonaceous material in aerosol samples has to be converted to $\mathrm{CO}_{2}$ and, for some AMS types, subsequently to graphite before it can be analyzed. In recent years, much progress has been made to reduce the sample size required for AMS measurements. This is advantageous for many applications, but it also places high requirements on the

\footnotetext{
${ }^{*}$ Corresponding author.

E-mail address: u.dusek@rug.nl
}

pre-treatment to introduce as little contamination as possible. For small samples this contamination can even become the limiting factor in the accuracy of the ${ }^{14} \mathrm{C}$ measurements (Klinedinst et al., 2000).

The ${ }^{14} \mathrm{C} /{ }^{12} \mathrm{C}$ ratio of a sample is reported relative to an oxalic acid standard (OXII) and in aerosol research it is usually expressed as fraction modern $\left(\mathrm{F}^{14} \mathrm{C}\right)$. The ${ }^{14} \mathrm{C} /{ }^{12} \mathrm{C}$ ratio of the OXII standard is related to the unperturbed atmosphere in the reference year of 1950 by multiplying it with a factor of 0.7459 (Mook et al., 1999; Reimer et al., 2004):

$$
F^{14} C=\frac{\left({ }^{14} C /{ }^{12} C\right)_{\text {sample },[-25]}}{0.7459 \times\left({ }^{14} C /{ }^{12} C\right)_{\text {OXII },[-25]}} .
$$

The ${ }^{14} \mathrm{C} /{ }^{12} \mathrm{C}$ ratio of the sample and standard are normalized to $\delta^{13} \mathrm{C}=-25 \%$.

For aerosol samples it is useful to measure radiocarbon separately on organic carbon (OC) and elemental carbon (EC). Methods for OC-EC separation rely on the different thermal resistivity of $\mathrm{OC}$ and $\mathrm{EC}$, with $\mathrm{OC}$ being more volatile and more easily combusted and EC more refractory. Usually OC is isolated from the sample by combustion or thermal desorption at lower temperatures and EC by combustion at higher 
temperatures. Special care has to be taken during the removal of OC to minimize the formation of pyrolysis products, which are very similar to the native EC in the sample and therefore contaminate the isolated EC fraction. To this end, various methods for OC-EC separation have been developed in the recent years that remove $\mathrm{OC}$ at several temperature steps in either pure $\mathrm{O}_{2}$ (Szidat et al., 2004; Dusek et al., 2014) or He flow (Liu et al., 2017), or $\mathrm{O}_{2}$ followed by $\mathrm{He}$ steps (Zhang et al., 2012; Bernardoni et al., 2013). A recent inter-comparison has shown that three methods in pure $\mathrm{O}_{2}$ and $\mathrm{O}_{2} / \mathrm{He}$ give similar results for $\mathrm{F}^{14} \mathrm{C}$ of the extracted $\mathrm{OC}$ and EC (Zenker et al., 2017), at least for a limited number of filter samples. An earlier inter-comparison showed that a wider range of methods give comparable results for $\mathrm{OC}$ and total carbon, but definite conclusions regarding $\mathrm{F}^{14} \mathrm{C}$ of $\mathrm{EC}$ were not possible in that study (Szidat et al., 2013).

In this work we describe an automated system for combustion of EC and OC called AAC (Automated Aerosol Combustion system), which is a further development of the ACS system, described in (Dusek et al., 2014). The goal was to replace the labor-intensive manual extraction by a fully automated system that delivers purified $\mathrm{CO}_{2}$ samples with minimal contamination to allow for studies with high time resolution or size-resolved sampling. The objective of this work is to demonstrate the operation and quality assurance of the automated method, but not to evaluate or test any particular protocol, which has been the subject of previous studies (Zhang et al., 2012; Bernardoni et al., 2013; Dusek et al., 2014; Zenker et al., 2017).

\section{METHODS}

\section{System Setup and Operation}

Fig. 1 shows a schematic setup of the AAC system. The system consists of a combustion line at a pressure of $\sim 30$ mbar above ambient (on the left side of Fig. 1) and a $\mathrm{CO}_{2}$ purification and collection line at low pressure. The two parts of the system are separated by a needle valve.

Either helium or oxygen can be selected as carrier gas. The system currently contains two combustion units $(\mathrm{O} 1$ and $\mathrm{O} 2$, located downstream of shut-off valves G1 and G2) and storage units (blue glass vials downstream of valves B1-B4), but can be extended with up to six more. Each combustion unit consists of a front and a back oven. A schematic drawing of the oven system and the temperature profile in the front and back oven during normal operation is given in the appendix (Figs. S1 and S2). The sample is placed in the front oven and the back oven is filled with platinum catalyst to oxidize incomplete combustion products to $\mathrm{CO}_{2}$. A bypass line (at G3) allows to flush the system, while all combustion units are closed and a small purge flow (at G4) prevents dead volumes in the line after the ovens. After exiting a combustion unit, the carrier gas flow containing the combustion products passes an infrared gas analyzer (IRGA, Vaisala GMP343; 0-1000 ppm range; Vantaa, Finland) and a water trap filled with phosphorous pentoxide. The IRGA was calibrated against a high performance NDIR $\mathrm{CO}_{2}-\mathrm{H}_{2} \mathrm{O}$ detector (Model 7000, LICOR Inc., Lincoln, NE, USA) as described in the supporting material A2.

After the needle valve, an additional water trap, cooled by a dry ice/ethanol mixture, removes any remaining water vapor. Subsequently, the flow can be directed either to the OC collection line or to the EC collection line. Both lines contain a liquid nitrogen (LN2) trap, but the OC collection line additionally contains a reduction oven (O3) filled with $\mathrm{Cu}$ and $\mathrm{Ag}$, in which combustion by-products such as $\mathrm{SO}_{2}$, $\mathrm{NO}_{\mathrm{x}}$, or halogens are either removed or converted to noncondensible gases. For EC this is not necessary, since

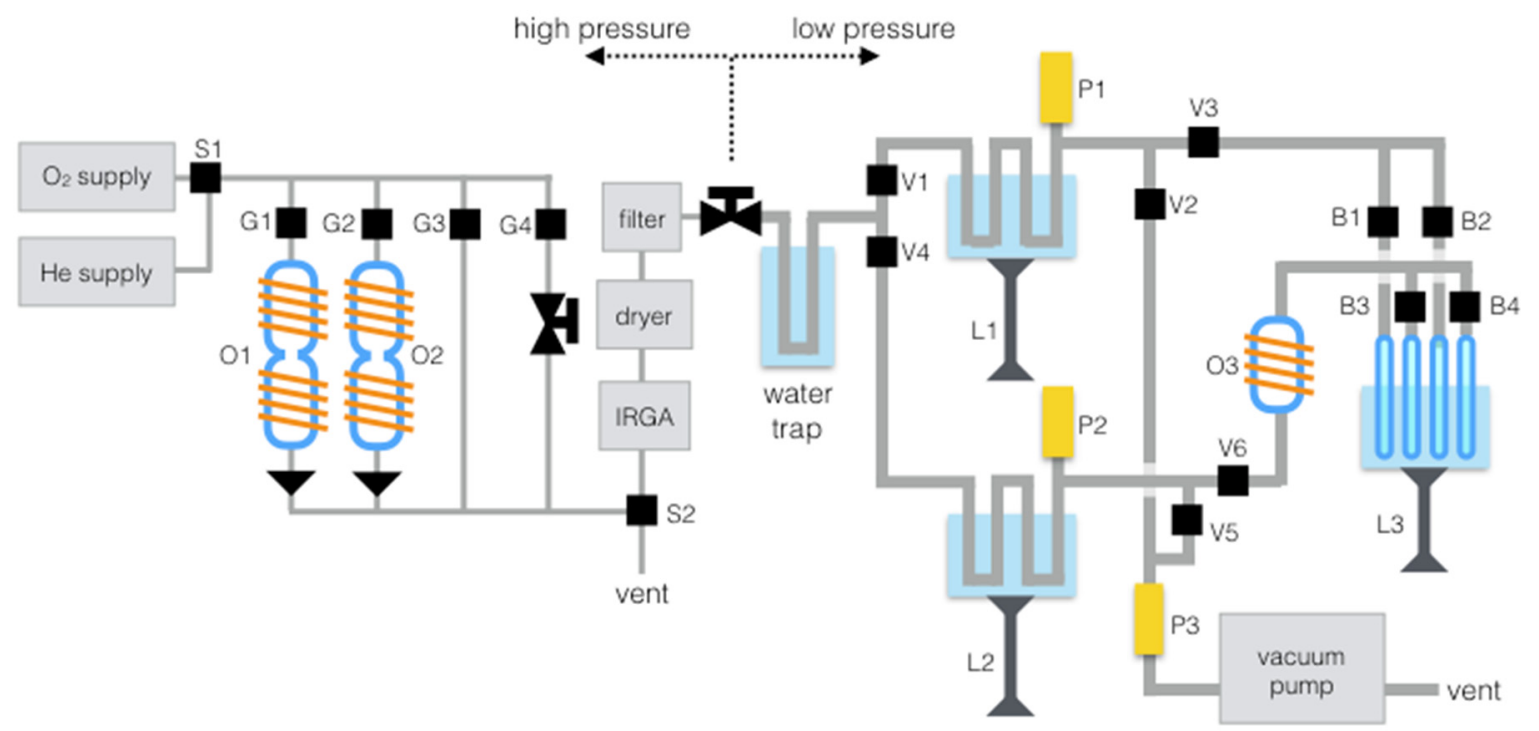

Fig. 1. A schematic diagram of the AAC system. Valves are indicated as black squares, stainless steel tubing as grey lines, (quartz) glass parts in blue and pressure sensors in yellow. The system currently contains two ovens (O1, O2) to combust the samples, a $\mathrm{CO}_{2}$ analyzer to quantify the resulting amount of $\mathrm{CO}_{2}$ (IRGA), two liquid nitrogen traps for collecting $\mathrm{CO}_{2}$ from oven 1 and oven 2 respectively (L1, L2), a reduction oven (O3), and four storage vials located after valves (B1-B4), which are submersible in liquid nitrogen container L3. 
combustion of EC yields almost pure $\mathrm{CO}_{2}$. Condensation of oxygen in the liquid nitrogen traps is prevented by the low pressure after the needle valve. After collection of all condensable combustion products in either trap L1 or L2, that trap is evacuated, the container with LN2 is lowered and the gases are expanded again. At the same time the glass storage tubes (breakseals) are cooled with LN2 and the combustion products are transferred to them by cryogenic pumping. In the $\mathrm{OC}$ collection line the combustion products pass the reduction oven, where $\mathrm{SO}_{2}, \mathrm{NO}_{\mathrm{x}}$, and halogens are removed. After $\mathrm{CO}_{2}$ is transferred, the storage tubes are evacuated and closed by valves (B1-B4) until all combustions have finished, at which point they are flame sealed and removed from the system.

\section{Combustion and Collection of $O C$ and $E C$}

The system is fully automated using a programmable logic controller (PLC) and custom software that allows for user defined temperature protocols. Per temperature protocol at most two carbon fractions can be collected, one in the OC line and one in the EC line. In principle any temperature protocol, involving temperature steps in He and/or oxygen can be run on the system, making the use of it very flexible. To illustrate a typical system operation we show a filter analysis, using the 2-step $\mathrm{O}_{2}$ protocol, which has been previously designed and tested by (Dusek et al., 2014) as an example. In this protocol the carrier gas is pure $\mathrm{O}_{2}$ in all temperature steps. The flow rate is adjustable, and has ben set to $100 \mathrm{~mL} \mathrm{~min}^{-1}$ for the pure $\mathrm{O}_{2}$ protocol.

Fig. 2 shows the set point and actual temperatures of the ovens (upper panel), the $\mathrm{CO}_{2}$ amount measured by the IRGA (middle panel), and the pressures recorded in the EC line at $\mathrm{P} 1$ in green and the $\mathrm{OC}$ line at $\mathrm{P} 2$ in yellow on a logarithmic scale (lower panel). At the start of the sequence, the back oven with the catalysts is heated to $650^{\circ} \mathrm{C}$ and remains at this temperature throughout the whole extraction. At the end of the extraction it is briefly heated to $700^{\circ} \mathrm{C}$ to clean potential buildup of material in the area of the small temperature drop between the ovens (Fig. S2). The sample is manually inserted into the front ovens, which are then analyzed sequentially according to the chosen protocol. During a typical OC-EC protocol the oven is first flushed to the vent, resulting in a small $\mathrm{CO}_{2}$ peak, as the ambient air is flushed out of the system. Approximately 8 minutes after starting the temperature protocol, the $\mathrm{O} 2$ flow is redirected to the OC collection line and the OC trap I is cooled by raising lift 2 (L2). This can be seen by an increased pressure in the OC line (yellow). Subsequently, the temperature of the front oven is raised to $375^{\circ} \mathrm{C}$ (blue line), and reaches the set point typically within $30 \mathrm{~s}$. The $\mathrm{CO}_{2}$ peak from combusted

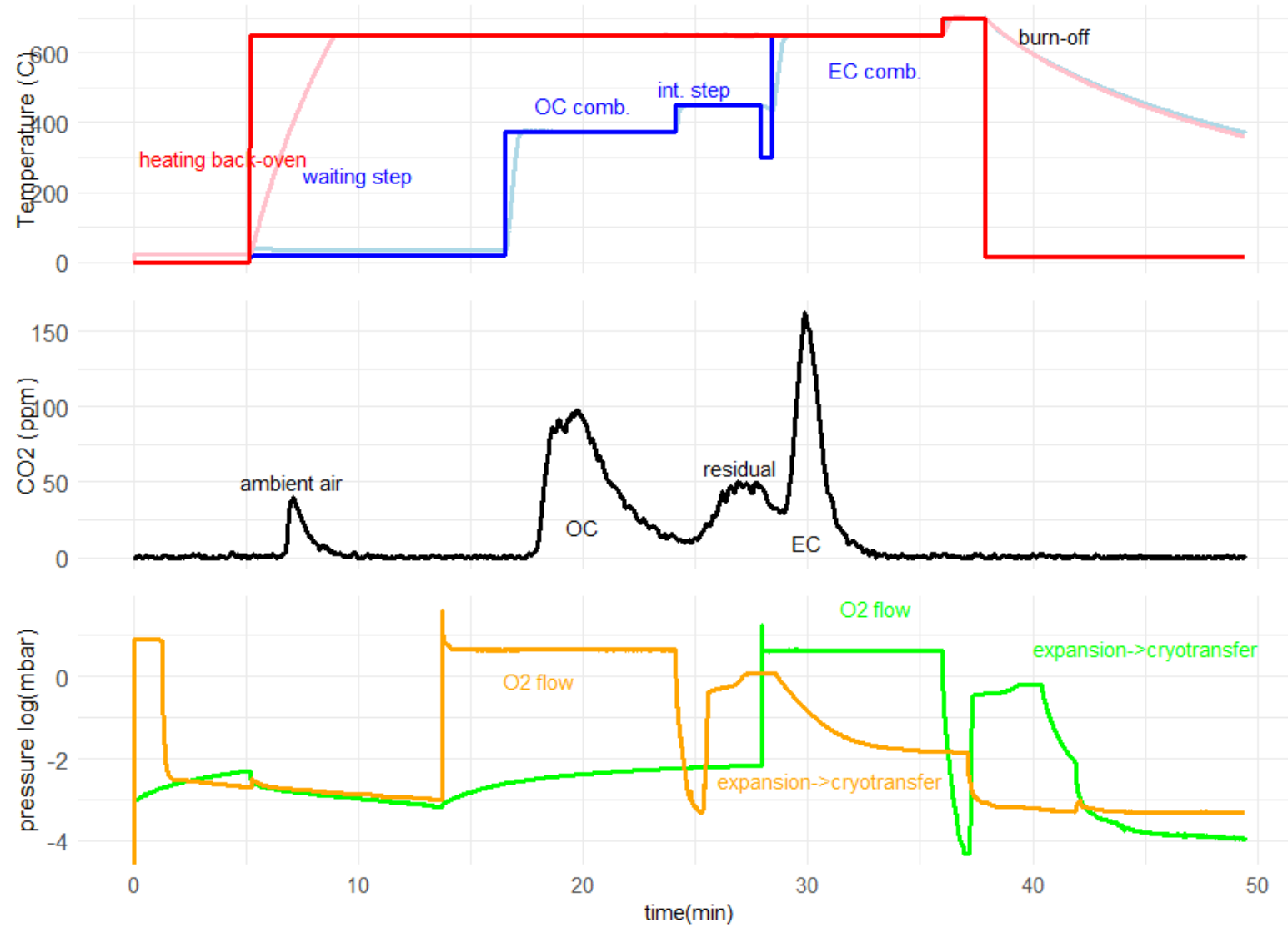

Fig. 2. Time series of oven temperature, $\mathrm{CO}_{2}$ concentration and pressure in measured in the OC and EC line during a typical OC-EC extraction. Upper panel: setpoint and actual temperature in the back oven (dark and light red lines, respectively) and in the front oven (dark and light blue lines). Middle panel: $\mathrm{CO}_{2}$ concentration measured by the IRGA detector. Lower panel: Pressure recorded at sensor P1 on the EC trap (green line) and P2 on the OC trap (yellow line). 
OC is detected by the IRGA. After OC combustion the temperature in the front oven is increased to $450^{\circ} \mathrm{C}$ and a mixture of the most refractory $\mathrm{OC}$ and less refractory EC is combusted and the resulting $\mathrm{CO}_{2}$ is discarded via the vent. This results in a less than $100 \%$ recovery of OC and EC, which is common practice in radiocarbon analysis of aerosol samples (e.g., Zhang et al., 2012; Bernardoni et al., 2013; Dusek et al., 2014). Meanwhile the OC line is evacuated, as evidenced by the pressure drop in the OC line, and the combustion products are released from the trap into the volume enclosed by V4, V5, and V6 in Fig. 1. The pressure increases in two steps: first combustion products such as $\mathrm{CO}_{2}$ evaporate, followed by thermal expansion as the trap warms to room temperature. Additionally some combustion products with higher boiling points, such as $\mathrm{SO}_{2}$ can be released during the thermal expansion. Subsequently, the released gases are transferred to the breakseals via cryogenic pumping and the pressure in the OC line gradually decreases. They pass the reduction oven, where $\mathrm{SO}_{2}$ is reduced to $\mathrm{S}$ and $\mathrm{NO}_{\mathrm{x}}$ to $\mathrm{N}_{2}$. The latter results in a small rest pressure in the system, which is evacuated before the valve on the breakseal is closed.

During the cryotransfer in the OC line, EC is combusted and collected in a similar manner as OC. The cryotransfer in the EC line proceeds much faster due to the absence of the reduction oven and $\mathrm{N}_{2}$ gas.

\section{Tests of $\mathrm{CO}_{2}$ Quantification and Purification}

The quantification of the $\mathrm{CO}_{2}$ amount by the IRGA was tested against an independent manometric method, where the $\mathrm{CO}_{2}$ collected in the breakseal was transferred to a preevacuated known volume, the resulting pressure was measured and the mass of $\mathrm{CO}_{2}$ calculated via the ideal gas law. This test also serves as an additional check for purity of the sample, since the IRGA only detects $\mathrm{CO}_{2}$, whereas the manometric method also detects increased pressure by possible contaminants that remain in the sample. If a sample is not sufficiently purified, the $\mathrm{CO}_{2}$ amount determined by the manometric method will be higher than the $\mathrm{CO}_{2}$ amount directly measured by the IRGA.

We tested the sample purification in the reduction oven by measuring the sample and residual gas after purification and $\mathrm{CO}_{2}$ collection. A quadrupole mass spectrometer (residual gas analyzer (RGA), model XT100, Extorr Inc., New Kensington, MA, USA) was used to analyze the mass spectrum of the purified sample and the residual gas in the system, after cryotransfer of the sample to the break seals. The purified sample was first collected in a sample flask, and introduced into the RGA. For measuring the composition of the residual gas the RGA was connected downstream of the AAC's vacuum pump, to where to residual gas was pumped away.

\section{Tests of Sample Contamination during Combustion}

Contamination introduced during the combustion process (blank) can be divided into two parts. A constant background contamination and a cross-contamination (or memory effect), where a given sample is contaminated by the residual carbon or $\mathrm{CO}_{2}$ in the system from the sample analyzed before.
Since the directly determined system blank (i.e., the amount of $\mathrm{CO}_{2}$ measured when no sample is introduced) is on the order of $<0.5 \mu \mathrm{g}$, it is much too small to be analyzed for ${ }^{14} \mathrm{C}$. Therefore the amount and $\mathrm{F}^{14} \mathrm{C}$ of the contamination are determined indirectly by combusting small amounts of standard material with known $\mathrm{F}^{14} \mathrm{C}$ values, namely the OXII standard with a nominal $\mathrm{F}^{14} \mathrm{C}$ value of 1.34066 and ${ }^{14} \mathrm{C}$ free standard (background wood) with $\mathrm{F}^{14} \mathrm{C}=0 .{ }^{14} \mathrm{C}$ measurements were conducted using the the Mini Carbon Dating System (MICADAS) AMS (Synal et al., 2007) at the Centre for Isotope Research at the University of Groningen using a gas inlet system (Ruff et al., 2007). The $\mathrm{F}^{14} \mathrm{C}$ values are corrected for memory effect (Wacker et al., 2010) and for instrument background (Salazar et al., 2015) and normalized to the average value of (memory and background corrected) gaseous OXII standards, which corrects for contamination introduced during the AMS measurement.

If contamination is introduced into the combustion, the measured $\mathrm{F}^{14} \mathrm{C}$ values of the standards will deviate from the nominal values and from this deviation the contamination can be estimated as follows. The contamination can be separated into two components: a fossil contamination $\left(\mathrm{M}_{\mathrm{fc}}\right.$, $\left.\mathrm{F}^{14} \mathrm{C}_{\mathrm{fc}}=0\right)$ and a modern contamination $\left(\mathrm{M}_{\mathrm{mc}}, \mathrm{F}^{14} \mathrm{C}_{\mathrm{mc}}=1\right)$. The measured mass $\left(\mathrm{M}_{\mathrm{m}}\right)$ and $\mathrm{F}^{14} \mathrm{C}_{\mathrm{m}}$ of any standard combusted on the system are given by:

$$
\begin{aligned}
& \mathrm{M}_{\mathrm{m}}=\mathrm{M}_{\mathrm{st}}+\mathrm{M}_{\mathrm{mc}}+\mathrm{M}_{\mathrm{fc}} \\
& \mathrm{F}^{14} \mathrm{C}_{\mathrm{m}} \mathrm{M}_{\mathrm{m}}=\mathrm{F}^{14} \mathrm{C}_{\mathrm{st}} \mathrm{M}_{\mathrm{st}}+\mathrm{F}^{14} \mathrm{C}_{\mathrm{mc}} \mathrm{M}_{\mathrm{mc}}+\mathrm{F}^{14} \mathrm{C}_{\mathrm{fc}} \mathrm{M}_{\mathrm{fc}} \\
& =\mathrm{F}^{14} \mathrm{C}_{\mathrm{st}} \mathrm{M}_{\mathrm{st}}+\mathrm{M}_{\mathrm{mc}},
\end{aligned}
$$

where $\mathrm{M}_{\mathrm{st}}$ is the unknown true mass of the standard and $\mathrm{F}^{14} \mathrm{C}_{\text {st }}$ can be 0 or 1.34066 , depending on the standard. We treat the true mass of the standard as unknown, since we do not weigh the standard to avoid introducing extra contamination.

The modern contamination can be estimated from the combustion of the ${ }^{14} \mathrm{C}$-free standard, which reduces Eq. (2) to

$\mathrm{M}_{\mathrm{mc}}=\mathrm{F}^{14} \mathrm{C}_{\mathrm{m}} \mathrm{M}_{\mathrm{m}}$

Knowing the $\mathrm{M}_{\mathrm{mc}}$, we can derive the fossil contamination, by combining Eqs. (1) and (2) and substituting $\mathrm{F}^{14} \mathrm{C}_{\mathrm{st}}=$ 1.34066 as:

$\mathrm{M}_{\mathrm{fc}}=\left(\left(1.34066-\mathrm{F}^{14} \mathrm{C}_{\mathrm{m}}\right) \mathrm{M}_{\mathrm{m}}-\left(\left(1.34066-\mathrm{F}^{14} \mathrm{C}_{\mathrm{mc}}\right) \mathrm{M}_{\mathrm{mc}}\right) /\right.$ 1.34066

The fraction modern of the total contamination can be calculated by mass balance:

$\mathrm{F}^{14} \mathrm{C}_{\mathrm{c}}=\mathrm{M}_{\mathrm{mc}} /\left(\mathrm{M}_{\mathrm{mc}}+\mathrm{M}_{\mathrm{fc}}\right)$

\section{Test Samples}

Ambient aerosol filter samples are used to assess the sample purification and quantification. These samples are collected on pre-cleaned $\left(800^{\circ} \mathrm{C}\right.$ for 4 hours $)$ quartz fiber substrates. After sampling the filters are kept in pre-cleaned 
aluminum foil and stored frozen until analysis. All material that came into contact with the filters during cutting and handling was pre-cleaned with acetone and ethanol and allowed to dry completely before use.

\section{RESULTS AND DISCUSSION}

After combustion, the condensable products are collected in trap P1 (EC) and P2 (OC). When liquid nitrogen is removed from the traps to expand the combustion products, we usually observe an increase in pressure (measured at $\mathrm{BB} 1$ or $\mathrm{BB} 2$ ) in two distinct steps, corresponding to the evaporation of more and less volatile combustion products, respectively. Fig. 3 shows a scatter plot of the pressure recorded $30 \mathrm{~s}$ after the liquid nitrogen removal vs. the pressure 180s seconds after liquid nitrogen removal for both EC and OC. After 30s only the most volatile combustion products $\left(\mathrm{CO}_{2}\right.$ and potentially $\left.\mathrm{NO}\right)$ have evaporated, where as at 180 s the pressure has stabilized which indicates that all combustion products have evaporated and the system has achieved thermal equilibrium. For EC, which is not expected to contain significant amounts of contaminants, the pressures measured after $30 \mathrm{~s}$ and $180 \mathrm{~s}$ are tightly correlated (Fig. 3(a)). A linear regression (solid line) indicates that the pressure after $180 \mathrm{~s}$ is approximately a factor of 1.1 higher than the pressure after $30 \mathrm{~s}$.

For OC the values are more scattered (Fig. 3(b)). As a comparison the linear fit derived for EC (Fig. 3(a)) is also plotted and shows the expected increase in pressure from the thermal expansion of gases evaporated after $30 \mathrm{~s}$. All data points lie above this line. This indicates the presence of gases such as $\mathrm{NO}_{\mathrm{x}}$ and $\mathrm{SO}_{2}$ in the combustion effluents of OC. The difference between the observed pressure at $180 \mathrm{~s}$ and the pressure expected from thermal expansion is a measure of their relative contribution. In most samples this contamination is small compared to the amount of $\mathrm{CO}_{2}$.

Fig. 4(a) shows mass spectra of the $\mathrm{CO}_{2}$ collected from the TC combustion of a typical filter sample after purification and Fig. 4(b) the mass spectrum of the rest gas that remains in the system after the $\mathrm{CO}_{2}$ is collected in the breakseal. The purified gas that is later fed into the AMS, shows the main peak at mass $44\left(\mathrm{CO}_{2}\right)$ as well as typical minor fragment peaks at mass $28(\mathrm{CO})$ and mass $16(\mathrm{O})$, but no other peaks, which confirms that the system yields pure $\mathrm{CO}_{2}$ after purification.
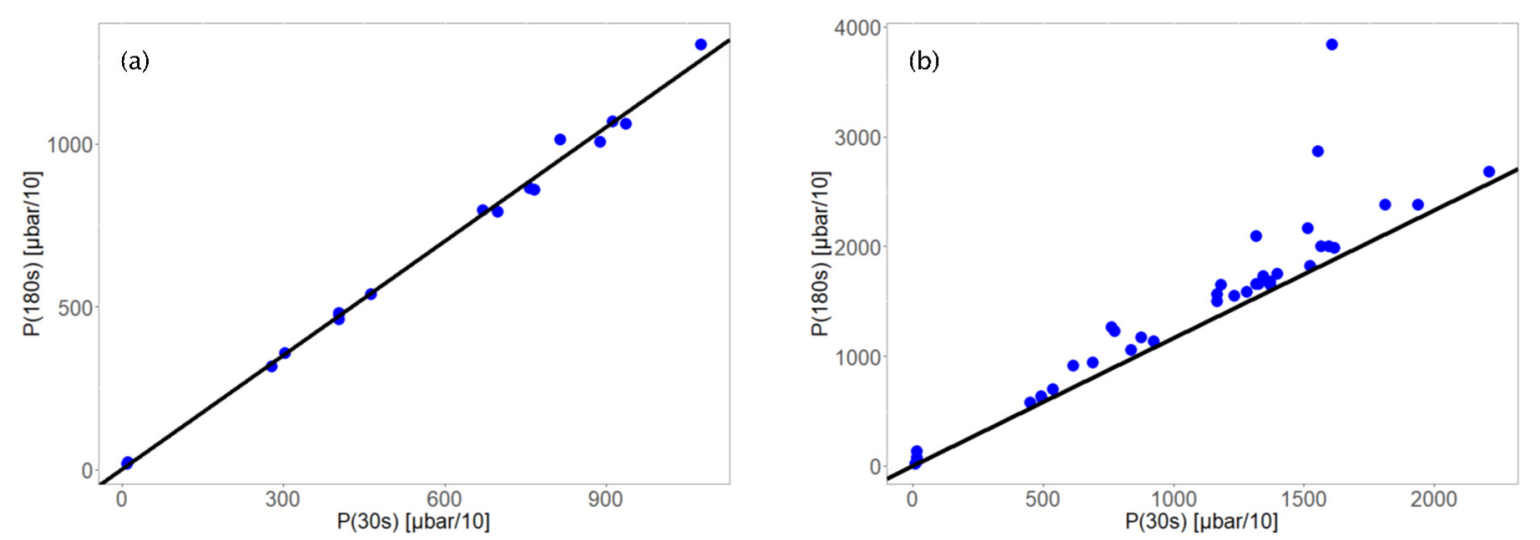

Fig. 3. A scatter plot of the gas pressure measured at two time periods during the evaporation of combustion products collected in trap 1 and 2: $180 \mathrm{~s}$ vs. $30 \mathrm{~s}$ after removing liquid nitrogen from the trap during (a) EC combustion; the combustion products are collected in trap P1 and the pressure during evaporation is measured in the volume enclosed by valves V1, V2 and V3 (see Fig. 1). (b) OC combustion; the combustion products are collected in trap P2 and the pressure during evaporation is measured in the volume enclosed by valves V4, V5 and V6. The black line indicated the best fit line for EC, shown in Fig. 3(a).
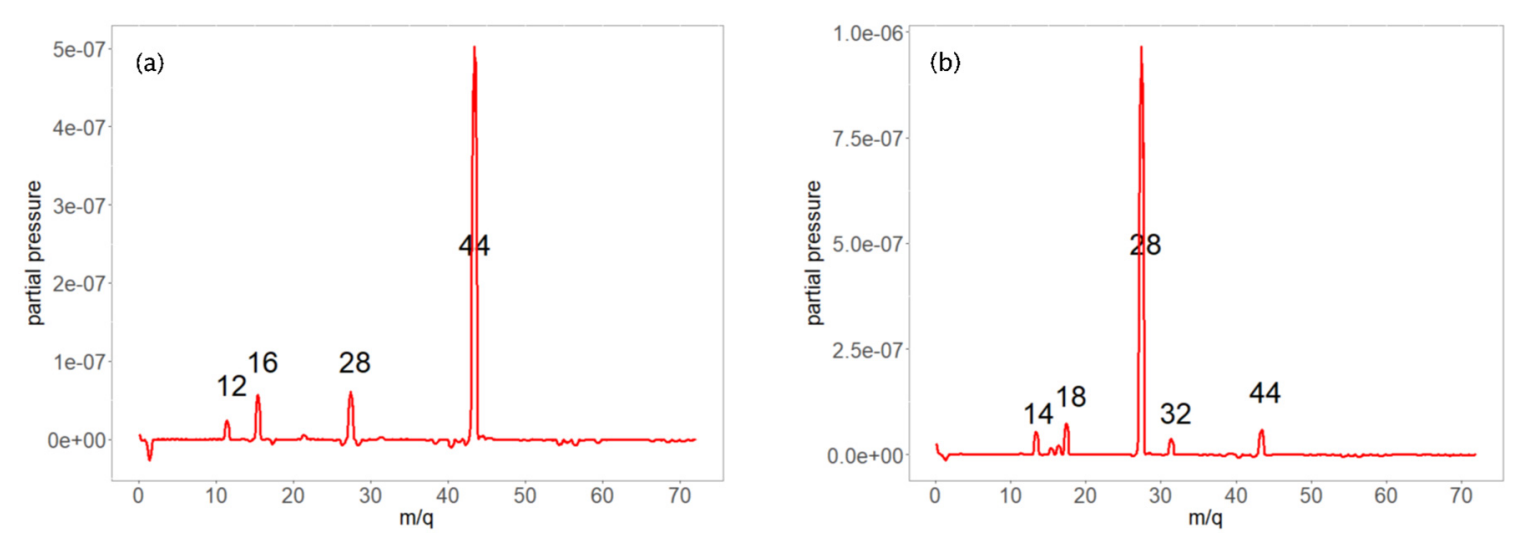

Fig. 4. The mass spectrum of (a) a typical the sample collected in the breakseal after TC extraction from a test filter sample; (b) the rest gas that remained after the $\mathrm{CO}_{2}$ was collected in the breakseal. 
The rest gas contains a major peak at mass 28, with a minor fragment at mass 14. This is a typical spectrum for $\mathrm{N}_{2}$, which results from the reduction of $\mathrm{NO}_{\mathrm{x}}$ and $\mathrm{N}_{2} \mathrm{O}$ in the copper oven. Further, there are traces of $\mathrm{CO}_{2}$ (mass 44) and water vapor (mass 18, with fragments at mass 17,16), but in very small amounts. Sulfur compounds are not present in either the collected sample or the rest gas.

The $\mathrm{CO}_{2}$ amount determined by the calibrated IRGA analyzer is evaluated against the manometrically determined $\mathrm{CO}_{2}$ amount of the final purified $\mathrm{CO}_{2}$ (Fig. 5) extracted from a number of ambient aerosol filter samples. The manometric measurement uses a calibrated volume of $2.5 \mathrm{~mL}$ and is conducted shortly before transferring the $\mathrm{CO}_{2}$ to the AMS. The slope of a linear fit through the data points is only slightly different from 1 and this excellent agreement shows that the IRGA is well calibrated for a wide range of sample sizes. $\mathrm{CO}_{2}$ samples resulting both from $\mathrm{OC}$ and $\mathrm{EC}$ combustion are included in Fig. 5. Since the IRGA only detects $\mathrm{CO}_{2}$, whereas the pressure in the calibrated volume is sensitive also to other gases potentially present in a not sufficiently purified sample, the agreement between the two methods also gives additional confirmation of the successful purification of the $\mathrm{CO}_{2}$ samples.
Fig. 6 shows the $\mathrm{F}^{14} \mathrm{C}$ of standard materials (OXII and background wood) that were combusted on the ACS system. The $\mathrm{F}^{14} \mathrm{C}$ values were corrected for contamination introduced during AMS measurement (including the contamination in the used calibration materials). Therefore the deviation of the measured from the nominal value is caused solely by the contamination introduced during the combustion. For sufficiently large standards (mass $>\sim 250 \mu \mathrm{g}$ for OXII and $>\sim 100 \mu \mathrm{g}$ for background wood), the measured $\mathrm{F}^{14} \mathrm{C}$ values approach the nominal values within measurement uncertainties, indicating that the contamination of the samples is not significantly larger than those of the AMS calibration materials. For smaller standard amounts, the $\mathrm{F}^{14} \mathrm{C}$ values start to deviate from the nominal values and show considerable variability, indicating that the contamination is somewhat variable. The smaller standards were used to calculate modern $\left(\mathrm{M}_{\mathrm{mc}}\right)$ and fossil contamination $\left(\mathrm{M}_{\mathrm{fc}}\right)$ according to Eqs. (1)-(4). $\mathrm{M}_{\mathrm{mc}}$ was on $0.13 \pm 0.21 \mu \mathrm{g}$ and $\mathrm{M}_{\mathrm{fc}}$ was on average $0.87 \pm 0.61 \mu \mathrm{g}$ (average \pm standard deviation). The total contamination agrees well with directly determined blank amounts of $<1 \mu \mathrm{g}$. The variability of the contamination suggests that it is partially introduced during the sample handling. The larger fossil contamination indicates that

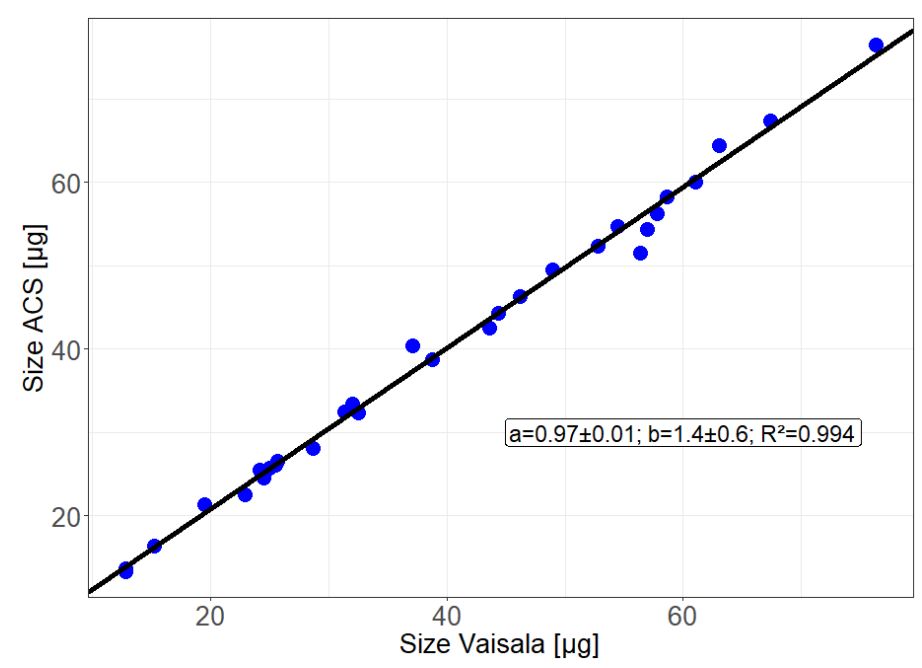

Fig. 5. The $\mathrm{CO}_{2}$ mass determined both by the calibrated IRGA (Vaisala) directly after the combustion oven against the $\mathrm{CO}_{2}$ mass of the final purified $\mathrm{CO}_{2}$, determined by a manometric method.
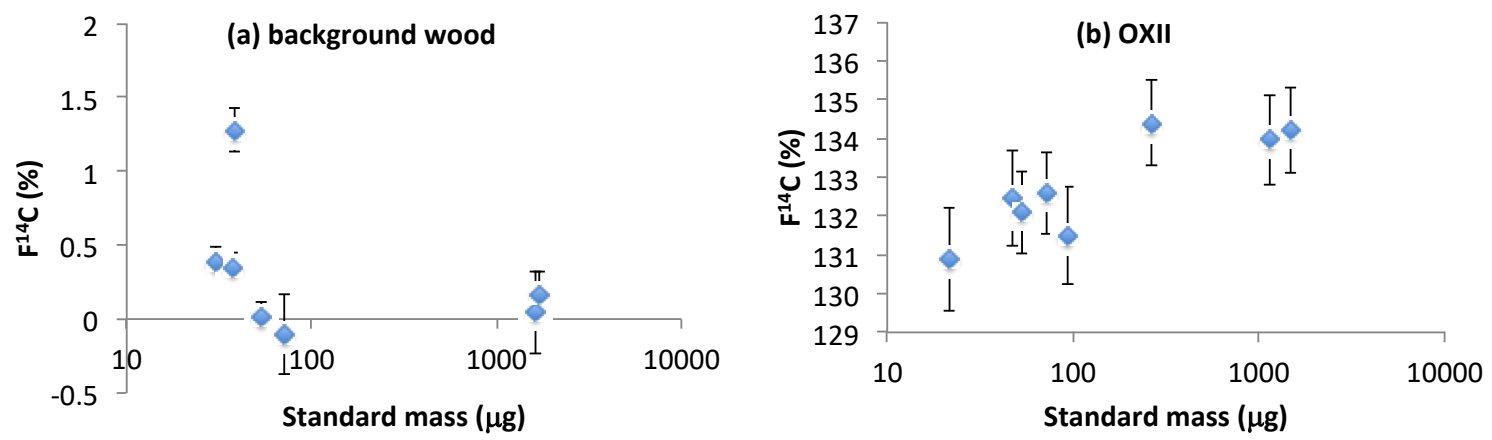

Fig. 6. $\mathrm{F}^{14} \mathrm{C}$ values of standard materials (OXII and a ${ }^{14} \mathrm{C}$ free wood; background wood) combusted on the system at $650{ }^{\circ} \mathrm{C}$ in pure $\mathrm{O}_{2}$. Standard materials were directly placed on a pre-cleaned filter without pre-weighing to avoid introducing extra contamination. 
cleaning agents used in our laboratory (e.g., ${ }^{14} \mathrm{C}$ free acetone) contributes to this contamination. However, the overall contamination is $1 \mu \mathrm{g}$ or less, which is relatively low. A larger contamination is usually introduced during filter sampling (field blank) and it is our recommendation to directly measure ${ }^{14} \mathrm{C}$ values of the field blanks and use these for correction of aerosol samples, if available, rather than the values determined here, as in that way the total contamination is accounted and corrected for.

Potential cross-contamination was investigated by alternately combusting OXII and background wood standards with masses between $20-100 \mu \mathrm{g}$, which are in the range of aerosol samples typically combusted on this system. Fig. 7 shows $\mathrm{F}^{14} \mathrm{C}$ values of the standards in the order in which they were combusted. This demonstrates that background wood standards combusted immediately after OXII standards do not show elevated ${ }^{14} \mathrm{C}$ values and ${ }^{14} \mathrm{C}$ values of OXII combusted after background wood are not decreased. Therefore cross-contamination for sample sizes below $100 \mu \mathrm{g}$ can be neglected. As a further test we combusted a small OXII sample directly after a very large background wood standard (mass $>1.7 \mu \mathrm{g}$ ). For this sample we identified an increased fossil contamination $\left(\mathrm{M}_{\mathrm{fc}}=3.4 \mu \mathrm{g}\right)$, which corresponded to a cross-contamination of approximately $0.15 \%$ of the mass of the previous wood standard. This confirms that cross-contamination for samples in the $<100 \mu \mathrm{g}$ range is negligible.

\section{CONCLUSIONS}

The automated combustion system described in this study is optimized for extracting organic and elemental carbon from aerosol samples for ${ }^{14} \mathrm{C}$ analysis. When extended to a total of eight ovens, eight samples can be processed fully automatically. Evaluation of the system shows that it produces purified $\mathrm{CO}_{2}$ samples with $\mathrm{SO}_{2}, \mathrm{NO}_{\mathrm{x}}, \mathrm{H}_{2} \mathrm{O}$, and halogens arising from combustion of inorganic aerosol constituents successfully removed. $\mathrm{CO}_{2}$ amounts measured with a calibrated NDIR sensor agree well with an independent manometric method. Combustion of standard materials

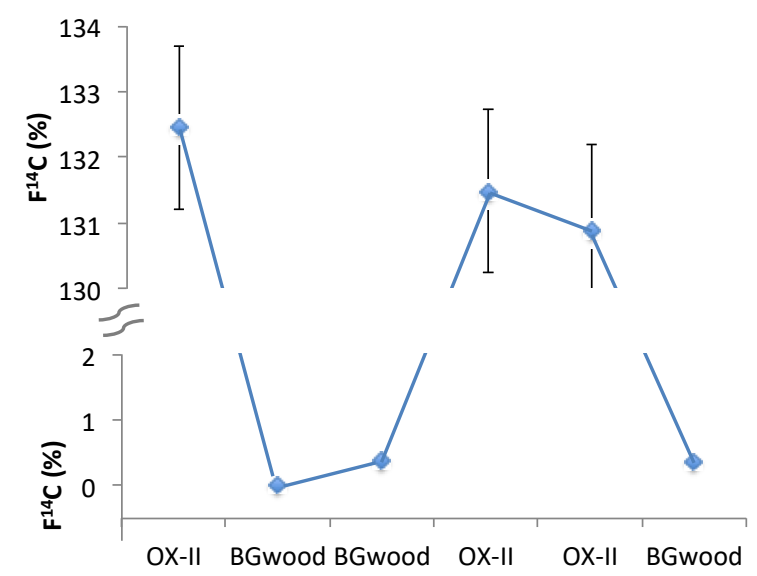

Fig. 7. $\mathrm{F}^{14} \mathrm{C}$ values of standard materials $\mathrm{OXII}$ and background wood (BGwood), shown in the sequence in which they were combusted. indicates that the contamination introduced during sample handling and combustion is about $1 \mu \mathrm{g}$ and has a dominantly fossil contribution.

\section{ACKNOWLEDGEMENTS}

${ }^{14} \mathrm{C}$ analyses for this work were supported by a KNAW project (no. 530-5CDP30). We thank Romke Tjoelker for help during the design and testing of the ACS system and Dipayan Paul, Marc Bleeker, Anita Aerts-Bijma, and Dicky van Zonneveld for their help with the AMS measurements and data evaluation at CIO.

\section{SUPPLEMENTARY MATERIAL}

Supplementary data associated with this article can be found in the online version at http://www.aaqr.org.

\section{REFERENCES}

Bernardoni, V., Calzolai, G., Chiari, M., Fedi, M., Lucarelli, F., Nava, S., Piazzalunga, A., Riccobono, F., Taccetti, F., Valli, G. and Vecchi, R. (2013). Radiocarbon analysis on organic and elemental carbon in aerosol samples and source apportionment at an urban site in Northern Italy. J. Aerosol Sci. 56: 88-99. doi: 10.1016/j.jaerosci.2012.06. 001

Currie, L.A. (2000). Evolution and multidisciplinary frontiers of 14C aerosol science. Radiocarbon 42: 115-126.

de Rooij, M., van der Plicht, J. and Meijer, H.A.J. (2010). Porous iron pellets for AMS 14C analysis of small samples down to ultra-microscale size (10-25 ugC). Nucl. Instrum. Methods Phys. Res., Sect. B 268: 947-951. doi: 10.1016/j.nimb.2009.10.071

Dusek, U., Monaco, M., Prokopiou, M., Gongriep, F., Hitzenberger, R., Meijer, H.A.J. and Röckmann, T. (2014). Evaluation of a two-step thermal method for separating organic and elemental carbon for radiocarbon analysis. Atmos. Meas. Tech. 7: 1943-1955. doi: 10.5194/amt-71943-2014

Dusek, U., Hitzenberger, R., Kasper-Giebl, A., Kistler, M., Meijer, H.A.J., Szidat, S., Wacker, L., Holzinger, R. and Röckmann, T. (2017). Sources and formation mechanisms of carbonaceous aerosol at a regional background site in the Netherlands: Insights from a year-long radiocarbon study. Atmos. Chem. Phys. 17: 3233-3251. doi: 10.5194/ acp-17-3233-2017

Glasius, M., la Cour, A. and Lohse, C. (2011). Fossil and nonfossil carbon in fine particulate matter: A study of five European cities. J. Geophys. Res. 116: D11302. doi: 10.1029/2011JD015646

Gustafsson, Ö., Krusa, M., Zencak, Z., Sheesley, R.J., Granat, L., Praveen, P.S., Rao, P.S.P., Leck, C. and Rodhe, H. (2009). Brown Clouds over South Asia: Biomass or fossil fuel combustion? Science 84: 495-499. doi: $10.1126 /$ science. 1164857

Heal, M.R. (2014). The application of carbon-14 analyses to the source apportionment of atmospheric carbonaceous particulate matter: A review. Anal. Bioanal.Chem. 406: 
81-98. doi: 10.1007/s00216-013-7404-1

Klinedinst, D.B. and Currie, L.A. (2000). Radiocarbon blank correction: Methodologies and limitations in a major urban study of carbonaceous aerosols. Nucl. Instrum. Methods Phys. Res., Sect. B 172: 545-550. doi: 10.1016/ S0168-583X(00)00233-0

Liu, J., Li, J., Zhang, Y., Liu, D., Ding, P., Shen, C., Shen, K., He, Q., Ding, X., Wang, X., Chen, D., Szidat, S. and Zhang, G. (2014). Source apportionment using radiocarbon and organic tracers for $\mathrm{PM}_{2.5}$ carbonaceous aerosols in Guangzhou, South China: Contrasting local- and regionalscale Haze events. Environ. Sci. Technol. 48: 1200212011. doi: 10.1021/es503102w

Liu, J., Li, J., Ding, P., Zhang, Y., Liu, D., Shen, C. and Zhang, G. (2017). Optimizing isolation protocol of organic carbon and elemental carbon for ${ }^{14} \mathrm{C}$ analysis using fine particulate samples. Atmos. Environ. 154: 9-19. doi: 10.1016/j.atmosenv.2017.01.027

Mook, W.G. and van der Plicht, J. (1999). Reporting ${ }^{14} \mathrm{C}$ activities and concentrations. Radiocarbon 41: 227-239.

Povinec, P.P., Litherland, A.E. and von Reden, K.F. (2009). Developments in radiocarbon technologies: from the libby counter to compound-specific AMS analyses. Radiocarbon 51: 45-78. doi: 10.2458/azu js rc.51.3478

Reimer, P.J., Brown, T.A. and Reimer, R.W. (2004). Discussion: Reporting and calibration of post-bomb ${ }^{14} \mathrm{C}$ data. Radiocarbon 46: 1299-1304.

Ruff, M., Wacker, L., Gäggeler, H., Suter, M., Synal, H. and Szidat, S. (2007). A gas ion source for radiocarbon measurements at $200 \mathrm{kV}$. Radiocarbon 49: 307-314.

Synal, H.A., Stocker, M. and Suter, M. (2007). MICADAS: A new compact radiocarbon AMS system. Nucl. Instrum. Methods Phys. Res., Sect. B 259: 7-13. doi: 10.1016/j.ni mb.2007.01.138.

Szidat, S., Jenk, T.M., Gäggeler, H.W., Synal, H.A., Hajdas, I., Bonani, G. and Saurer, M. (2004). THEODORE, a two-step heating system for the EC/OC determination of radiocarbon $\left({ }^{14} \mathrm{C}\right)$ in the environment. Nucl. Instrum. Methods Phys. Res., Sect. B 223-224: 829-836. doi: 10.1016/j.nimb.2004.04.153.

Szidat, S., Jenk, T.M., Synal, H.A., Kalberer, M., Wacker, L., Hajdas, I., Kasper-Giebl, A. and Baltensperger, U. (2006). Contributions of fossil fuel, biomass-burning, and biogenic emissions to carbonaceous aerosols in Zurich as traced by ${ }^{14}$ C. J. Geophys. Res. 111: D07206. doi: 10.1029/2005JD006590

Szidat, S., Bench, G., Bernardoni, V., Calzolai, G., Czimczik, C., Derendorp, L., Dusek, U., Elder, K., Fedi, M., Genberg,
J., Gustafsson, Ö., Kirillova, E., Kondo, M., McNichol, A., Perron, N., Santos, G., Stenström, K., Swietlicki, E., Uchida, M., Vecchi, R., Wacker, L., Zhang, Y. and Prévôt, A. (2013). Ontercomparison of ${ }^{14} \mathrm{C}$ analysis of carbonaceous aerosols: Excercise 2009. Radiocarbon 55: 1496-1509. doi: 10.2458/azu_js_rc.55.16314

van der Plicht, J., Wijma, S., Aerts, A., Pertuisot, M. and Meijer, H.A. (2000). Status report: The Groningen AMS facility. Nucl. Instruments Methods Phys. Res. B 172: 5865. doi: 10.1016/S0168-583X(00)00284-6

Winiger, P., Andersson, A., Yttri, K.E., Tunved, P. and Gustafsson, Ö. (2015). Isotope-based source apportionment of EC aerosol particles during winter high-pollution events at the Zeppelin Observatory, Svalbard. Environ. Sci. Technol. 49: 11959-11966. doi: 10.1021/acs.est.5b0 2644

Zenker, K., Vonwiller, M., Szidat, S., Calzolai, G., Giannoni, M., Bernardoni, V., Jedynska, A.D., Henzing, B., Meijer, H.A.J. and Dusek, U. (2017). Evaluation and intercomparison of oxygen-based OC-EC separation methods for radiocarbon analysis of ambient aerosol particle samples. Atmosphere 8: 226. doi: 10.3390/atmos8110226

Zhang, Y., Ren, H., Sun, Y., Cao, F., Chang, Y., Liu, S., Lee, X., Agrios, K., Kawamura, K., Liu, D., Ren, L., Du, W., Wang, Z., Prévôt, A.S.H., Szidat, S. and Fu, P. (2017). High contribution of nonfossil sources to submicrometer organic aerosols in Beijing, China. Environ. Sci. Technol. 51: 7842-7852. doi: 10.1021/acs.est.7b01517

Zhang, Y.L., Perron, N., Ciobanu, V.G., Zotter, P., Minguillón, M.C., Wacker, L., Prévôt, A.S.H., Baltensperger, U. and Szidat, S. (2012). On the isolation of OC and EC and the optimal strategy of radiocarbon-based source apportionment of carbonaceous aerosols. Atmos. Chem. Phys. 12: 1084110856. doi: 10.5194/acp-12-10841-2012

Zotter, P., Ciobanu, V.G., Zhang, Y.L., El-Haddad, I., Macchia, M., Daellenbach, K.R., Salazar, G.A., Huang, R.J., Wacker, L., Hueglin, C., Piazzalunga, A., Fermo, P., Schwikowski, M., Baltensperger, U., Szidat, S. and Prevot, A.S.H. (2014). Radiocarbon analysis of elemental and organic carbon in Switzerland during winter-smog episodes from 2008 to 2012-Part 1: Source apportionment and spatial variability. Atmos. Chem. Phys. 14: 1355113570. doi: 10.5194/acp-14-13551-2014

Received for review, June 4, 2019 Revised, October 11, 2019 Accepted, October 11, 2019 